\title{
PENGGUNAAN PENDEKATAN KETERAMPILAN PROSES DALAM PEMBELAJARAN PERKEMBANGAN PESERTA DIDIK UNTUK MENGINGKATKAN HASIL BELAJAR MAHASISWA PRODI BAHASA INGGRISSEMESTER IIC FKIP - UNMAS DENPASAR TAHUN AKADEMIK 2012/2013
}

\author{
Putu Sri Astuti \\ Fakultas Keguruan dan Ilmu Pendidikan \\ Universitas Mahasaraswati Denpasar
}

\begin{abstract}
This research is motivated by: (1) low student achievement; (2) low activity of student learning; (3) learning methodless attractive, making it less motivating for studentstolearn; (4) the students sometimes difficult to understandand developa concept that they never experienced directly. The purpose of this research is to improve student achievement using process skills approach and improve students learning activities through processs kills approach. Subjects were students of second semester C English Education Study Program Guidance and Counseling Unmas Denpasar with 40 students. Data collection method used is an essay test to determine student achievement. Data were analyzed with descriptive statistical analysis methods. The research method used was action research as much as 2 cycles. Each cycle with the basic steps: planning, acting, observing, reflecting, with arevised actionis always used to find a better and accurate results. The analysis shows an increasing in learning outcomes of second semester $C$ English Study Program FKIP Unmas Denpasar students with the initial mean 1,97 which is in low catagory, the first cycle is 2,45 in the medium catagory, and 3,125 point at the second cycle which is in high catagory, and the student learning activities with the subject of development of students are also increasing. Therefore in this class action research, process skills approach is proven that it can incrases the students learning achievment.
\end{abstract}

Keywords: Process Skills Approach and Learning Achievement 


\section{PENDAHULUAN}

Menurut Undang-Undang No. 20 tahun 2003 tentang Sistem Pendidikan Nasional Bab VI pasal 14 "Jenjang pendidikan formal terdiri atas pendidikan dasar, pendidikan menengah, dan pendidikan tinggi” Jenjang pendidikan dasar terdiri dari SD dan SLTP, jenjang pendidikan menengah yaitu SMA dan SMK, dan jenjang pendidikan tinggi yaitu, Sekolah Tinggi, Akademi, Institut, dan Universitas. Pendidikan tinggi khususnya FKIP adalah merupakan LPTK yang memproduksi calon guru yang profesional untuk itu penanaman konsep sangat penting. Penanaman konsep dalam pembelajaran perkembangan peserta didik sangat berhubungan dengan penerapan pendekatan keterampilan proses di mana mahasiswa harus dapat memahami konsep-konsep yang diberikan dalam proses pembelajaran. Diharapkan konsep tersebut nantinya akan melekat terus pada diri mahasiswa sebagai pengetahuan awal dalam memahami tumbuh kembangnya peserta didik. Oleh karena mata kuliah perkembangan peserta didik untuk dipahami oleh mahasiswa apabila terjadi kesalahan pada konsep yang diberikan akan berakibat sangat fatal dan akan sangat sulit untuk mengubah konsep yang telah melekat pada diri mahasiswa. Sebuah konsep akan lebih dapat dipahami oleh mahasiswa apabila melihat, melakukan, dan menemukan masalah tersebut seperti istilah learning by doing yang artinya belajar sambil melakukan. Namun dalam kenyataannya, mahasiswa hanya menerima informasi tentang materi yang lebih banyak bersifat teoritis dan mahasiswa belajar dengan cara menghafal yang mengakibatkan materi tersebut mudah untuk dilupakan. Demikian juga dengan presetasi dan aktivitas dalam pembelajaran yang ditunjukan oleh mahasiwa kurang maksimal. Untuk itu cara mengajar seperti itu harus ditinggalkan karena dengan kegiatan pembelajaran teoritis (verbal) menghasilkan produk tanpa mengajarkan proses. Kondisi ini disebabkan karena, dosen

kurang memahami atau kurang persiapan dalam mengajarkan proses pada mahasiswa.

Kemampuan mahasiswa hanya dalam aspek kognitif atau pengetahuan saja bila dilihat dari keterampilannya dalam berinteraksi dengan temantemannya. Hal itu terjadi karena proses pembe- lajaran lebih banyak bersifat teoritis dan hapalan. Untuk itu diperlukan kemampuan dosen mengemas sistem pembelajaran agar siswa menjadi aktif dalam proses pembelajaran dari proses menemukan masalah, mencari solusi, hingga dapat menemukan sebuah konsep. Pendekatan yang sesuai dengan penanaman konsep dalam perkembangan peserta didik adalah pendekatan keterampilan proses. Pendekatan ini telah dikenal oleh dosen namun dalam proses pembelajaran belum sepenuhnya dipergunakan.

Dengan menggunakan pendekatan keterampilan proses mahasiswa memiliki keterampilan dalam menemukan suatu konsep dan akhirnya bermuara pada tingkat hasil belajar mahasiswa. Mahasiswa akan lebih memahami materi bila terlihat langsung yang ada pada kerucut pengalaman Edgar Dale berada pada tingkat paling bawah. Dalam kerucut pengalaman Edgaar Dale ada 11 tingkatan pengalaman belajar dari tingkat yang paling konkret sampai yang paling abstrak. Pengalaman langsung merupakan pengalaman belajar yang paling kongkret.

Berdasarkan latar belakang tersebutdi atas diadakan penelitian tindakan kelasdengan judul: Penggunaan Pendekatan Keterampilan Proses Dalam Pembelajaran Perkembangan Didik Untuk Meningkatkan Hasil Belajar Mahasiswa Prodi Pendidikan Bahasa Inggris FKIP UNMAS Denpasar Tahun 2012/2013. Adapun masalah yang diangkat dalam penelitian ini adalah (1) Bagaimanakah pendekatan keterampilan proses dalam meningkatkan dapat prestasi belajar mahasiswa semester IIC program studi Bahasa Inggris FKIP Unmas Denpasar tahun akademik 2012/2013? (2) Bagaimanakah pendekatan keterampilan proses dalam meningkatkan aktivitas belajar mahasiswa semester genap program studi Bahasa Inggris FKIP Unmas Denpasar tahun akademik 2012/2013?

\section{METODE PENELITIAN}

\section{A. Jenis Penelitian}

Penelitian ini menggunakan penelitian tindakan kelas. Penelitian Tindakan kelas (classroom action research) adalah suatubentuk 
penelitian yang bersifat reflektif dengan melakukan tindakan-tindakan tertentu dengan tujuan meningkatkan hasil belajar di kelas secara profesional. Rancangan penelitian tindakan kelas dilaksanakan dengan berpedoman pada PTK dari Kemmis dan Mc.Taggart. Model PTK seperti dalam buku Pedoman Pelaksanaan Penelitian Tindakan Kelas ( Suyanto, 1997) adalah sebagai berikut.

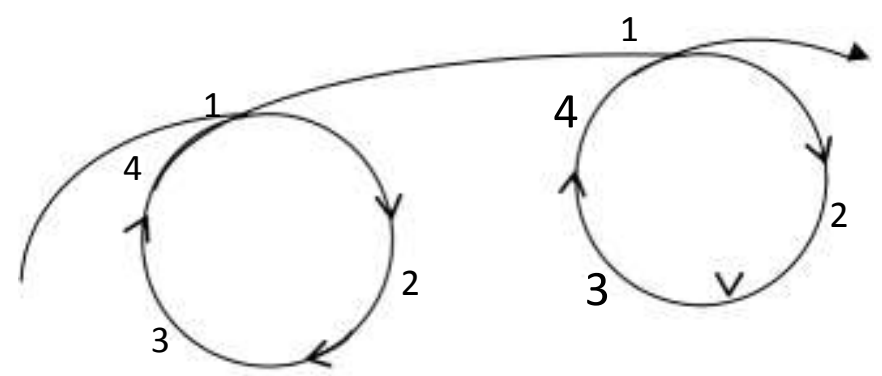

\section{Gambar 01 Model PTK 2 Siklus}

Keterangan :

1. Tahap rencana

2. TahapTindakan

3. Tahap Observasi

4. Tahap Refleksi

Penelitian tindakan kelas pada penelitian inidilaksanakan dua siklus dan tiap siklus terdiri dari 4 tahap yaitu rencana, tindakan, observasi dan refleksi.Setiap siklus terdiri dari 3 pertemuan.

Dalam penelitian ini setiap pertemuan dilaksanakan proses pembelajaran dengan menggunakan pendekatan keterampilan proses

\section{B. Subyek Penelitian}

Subyek penelitian tindakan kelas ini adalah mahasiswa semester II C Prodi Pendidikan Bahasa Inggris FKIP Unmas Denpasar tahun akademik 2012/2013 yang berjumlah 40 orang.

\section{Prosedur Penelitian}

Penelitian ini dilaksanakan dalam dua siklus dan tiap siklus terdiri dari empat tahap.Prosedur penelitian adalah sebagai berikut.

\section{SIKLUS I}

1. Rencana

a. Menyiapkan bahan ajar untuk menyusun skenario pembelajaran seperti satuan acara perkuliahan (SAP), silabus, buku sumber, buku penunjang yang relevan serta sarana yang lain

b. Menyiapkan skenario pembelajaran yang akan digunakan dalam mengajar c. Menyiapkan media yang akan digunakan seperti LCD dan internet

2. Tindakan

a. Persiapan

1) Menyusun skenario pembelajaran sesuai dengan kompetensi dasar, hasil belajardan indikator yang akan diajarkan

2) Menyiapkan media yang akan digunakan

3) Menyiapkan instrumen penelitian berupa tes essay

b. Pelaksanaan

1) Melaksanakan proses pembelajaran sesuai dengan jadwal dan rencana pembelajaran yang sudah disiapkan

2) Setiap pertemuan menggunakan pendekatan keterampilan proses.

c. Observasi

Pada akhir proses pembelajaran dilakukan penilaian terhadap hasil belajar dengan menggunakan tes essay yang sudah disiapkan.

d. Refleksi

Setelah kegiatan evaluasi dilakukan, penelitian mengkaji dan merenungkan hasil penelitian terhadap pelaksanaan tindakan pada 
siklus I dengan tujuan untuk mengetahui hambatanhambatan atau masalah-masalah yang dialami serta memikirkan pemecahannya. Kemudian dilanjutkan pada siklus II dengan menggunakan tindakan yang sama.

\section{Instrumen dan Teknik pengumpulan Data}

Data dalam penelitian ini menggunakan metode tes dan observasi, yang dimaksud dengan metode tes adalah cara memperoleh data yang berbentuk suatu tugas yang harus dikerjakan oleh seorang atau sekelompok orang yang di tes (tes tee), (AAGede Agung, 1999). Kegunaan metode tes adalah untuk memperoleh data tentang hasil belajar perkembangan peserta didik .Alat pengumpul data menggunakan lembar tes. Sedangkan metode observasi adalah mcara untuk mengamati partisipasi mahasiswa dalam kegiatan pembelajaran

\section{E. Analisis data}

Analisis data yang digunakan adalah analisis data deskriptif kuantitatif yaitu menyusun data secara sistematis dari yang besar ke yang kecil atau sebaliknya untuk ditarik suatu simpulan. Teknik deskriftif kuantitatif adalah suatu teknik yang menggunakan paparan sederhana yang berkaitan dengan angka dan persentase mengenai mengenai obyek yang diteliti, sehingga memperoleh kesimpulan umum. Data hasil observasi berupa aktifitas siswa dalam pembelajaran. Selanjutnya untuk memperoleh atau mencari nilai rata-rata digunakan rumus sebagai berikut:

$$
M=\frac{{ }^{f x}}{N}
$$

Penerapan teknik ini dilakukan dengan mencari persentase hasil belajar mahasiswa yang kemudian dikonversikan dengan pedoman PAP skala 5 seperti tabel di bawah ini

Tabel 01 Pedoman PAP Skala 5

\begin{tabular}{|c|c|c|}
\hline Persentase & Nilai & Katagori \\
\hline $90-100$ & A & Sangat Tinggi \\
$80-89$ & B & Tinggi \\
$65-79$ & C & Sedang \\
$55-64$ & D & Kurang \\
$0-54$ & E & Sangat Kurang \\
\hline
\end{tabular}

\section{HASIL PENELITIAN DAN PEMBAHASAN}

\section{Hasil Penelitian}

Dari pelaksanaan penelitian diperoleh data tentang peningkatan hasil pelajar dan aktivitas mahasiswa dalam pembelajaran mata kuliah Perkembangan Peserta Didik melalui Pendekatan Ketrampilan Proses dengan obyek sasaran Mahasiswa Prodi Pendidikan Bahasa Inggris semester II C tahun akademik 2012/2013, dengan prosedur yang sesuai dengan tahapannya.

Penelitian ini dilaksanakan dalam dua siklus pembelajaran, siklus I yaitu peningkatan hasil belajar perkembangan peserta didik dan aktivitas mahasiswa dalam pembelajaran dan siklus II ditekankan perbaikan berdasarkan pada kegagalankegagalan yang ditemui pada siklus I. Pelaksanaan penelitian ini diawali dengan memberikan tes awal pada hari Rabu 12 Juni 2013 sebelum dilaksanakan tindakan pembelajaran, maka di peroleh hasil sebagai berikut dalam tabel 2 di bawah ini.

Tabel 2 Analis data Hasil Tes Awal dalam Mata Kuliah Perkembangan Peserta Didik

\begin{tabular}{|c|c|c|c|c|c|c|}
\hline No. & Katagori & $\begin{array}{l}\text { Skor } \\
\text { Standar } \\
\text { (x) }\end{array}$ & $\begin{array}{l}\text { Frekuensi } \\
\text { (f) }\end{array}$ & $\begin{array}{c}\text { Jumlah } \\
\text { Nilai (fx) }\end{array}$ & Persen (\%) & Rata-rata nilai \\
\hline (1) & (2) & (3) & (4) & (5) & (6) & (7) \\
\hline 1. & Sangat Tinggi & 4 & 0 & $\overline{0}$ & $0 \%$ & \\
\hline 2. & Tinggi & 3 & 10 & 30 & $25 \%$ & \\
\hline 3. & Sedang & 2 & 18 & 36 & 45,5 & 78 \\
\hline 4. & Kurang & 1 & 12 & 12 & $30 \%$ & $\overline{40}$ \\
\hline 5. & Sangat Kurang & 0 & 0 & 0 & & $\begin{array}{c}=1,95 \\
\text { (Kurang) }\end{array}$ \\
\hline & & & 40 & 78 & $100 \%$ & \\
\hline
\end{tabular}


Berdasarkan tabel tersebut diperoleh hasilnya 1,95 termasuk katagori kurang dari standar yang ditetapkan untuk itu, dilakukan perbaikan pembelajaran melalui penelitian tindakan kelas dengan menggunakan pendekatan keterampilan proses dalam meningkatkan hasil pembelajaran perekembangan peserta didik yang dilaksanakan dalam dua siklus
Selanjutnya siklus I dilaksanakan pada hari Rabu tanggal 19 Juni 2013, ada peningkatan dari tes awal sebelum tindakan dengan pencapaian nilai rata-rata 2,45 katagori sedang. Adapun hasil analisis data tes kemampuan dalam pembelajaran perkembangan peserta didik dengan keterampilan pendekatan proses pada Mahasiswa semester $2 \mathrm{C}$ di Prodi Bahasa Inggris adalah sebagai berikut.

Tabel. 3 Analisis Data Hasil Tes kemampuan Pembelajaran Perkembangan Peserta Didik dengan Pendekatan Keterampilan proses Mahasiswa Semester II C Prodi Bahasa Inggris Pada Siklus I

\begin{tabular}{|c|c|c|c|c|c|c|}
\hline No. & Katagori & $\begin{array}{c}\text { Skor } \\
\text { Standar } \\
\text { (x) }\end{array}$ & $\begin{array}{l}\text { Frekuensi } \\
\text { (f) }\end{array}$ & $\begin{array}{c}\text { Jumlah } \\
\text { Nilai (fx) }\end{array}$ & Persen $(\%)$ & Rata-rata nilai \\
\hline (1) & (2) & (3) & (4) & (5) & (6) & (7) \\
\hline 1. & Sangat Tinggi & 4 & 4 & 16 & $10 \%$ & \\
\hline 2. & Tinggi & 3 & 15 & 45 & $37,5 \%$ & \\
\hline 3. & Sedang & 2 & 15 & 30 & $37,5 \%$ & 97 \\
\hline 4. & Kurang & 1 & 6 & 6 & $15 \%$ & $\overline{40}$ \\
\hline 5. & Sangat Kurang & 0 & 0 & 0 & & $=2,45$ \\
\hline & & & 40 & 97 & $100 \%$ & \\
\hline
\end{tabular}

Pada hasil tes siklus I melalui pendekatan keterampilan proses dalam peningkatan hasil belajar perkembangan peserta didik secara klasikal menunjukkan katagori sedang. Hal ini terlihat dari rata-rata nilai mencapai 2,45 dan belum memenuhi nilai standar yang ditetapkan yaitu sebesar 3 .

Kemudian dilanjutkan pelaksanaan siklus II pada hari Rabu, 26 Juni 2013, dimana hasil tes kemampuan pembelajaran perkembangan peserta didik melalui pendekatan keterampilan proses pada mahasiswa semester 2 C Prodi Bahasa Inggris FKIP Unmas Denpasar secara klasiskal menunjukkan peningkatan katagori tinggi, untuk itu dapat dilihat pada table berikut.

Tabel. 4 Analisis Data Hasil Tes kemampuan Pembelajaran Perkembangan Peserta Didik dengan Pendekatan Keterampilan proses Mahasiswa Semester II C Prodi Bahasa Inggris Pada Siklus II

\begin{tabular}{|c|c|c|c|c|c|c|}
\hline No. & Katagori & $\begin{array}{c}\text { Skor } \\
\text { Standar } \\
(\mathrm{x})\end{array}$ & $\begin{array}{l}\text { Frekuensi } \\
\text { (f) }\end{array}$ & $\begin{array}{c}\text { Jumlah } \\
\text { Nilai (fx) }\end{array}$ & Persen (\%) & Rata-rata nilai \\
\hline (1) & (2) & (3) & (4) & (5) & (6) & (7) \\
\hline 1. & Sangat Tinggi & 4 & 10 & 40 & $25 \%$ & \\
\hline 2. & Tinggi & 3 & 15 & 45 & $37,5 \%$ & \\
\hline 3. & Sedang & 2 & 15 & 30 & $37,5 \%$ & $\underline{125}$ \\
\hline 4. & Kurang & 1 & 0 & 0 & $0 \%$ & $\overline{40}$ \\
\hline \multirow[t]{3}{*}{5.} & Sangat Kurang & 0 & 0 & 0 & & $=3,125$ \\
\hline & & & & & & (Tinggi) \\
\hline & & & 40 & 97 & $100 \%$ & \\
\hline
\end{tabular}

\section{Pembahasan}

Berdasarkan hasil analisis pada tes awal, siklus I dan siklus II seperti yang telah disajikan di atas dapat di katakan bahwa hasil penelitian menunjukkan adanya peningkatan yang signifi- kan yaitu angka rata-rata awal siklus 1,95 katagori kurang, siklus I 2,45 katagori sedang dan siklus II nilai rata-rata 3,125 katagori tinggi. Dengan demikian dapat dinyatakan bahwa penggunaan pendekatan keterampilan proses 
dalam pembelajaran perkembangan peserta didik untuk semester $2 \mathrm{C}$ prodi bahasa inggris FKIP Unmas Denpasar tahun akademik 2012/2013 cendrung meningkatkan hasil belajar perkembangan peserta didik mahasiswa.Untuk peningkatan itu, dapat dilihat pada grafik di bawah ini.

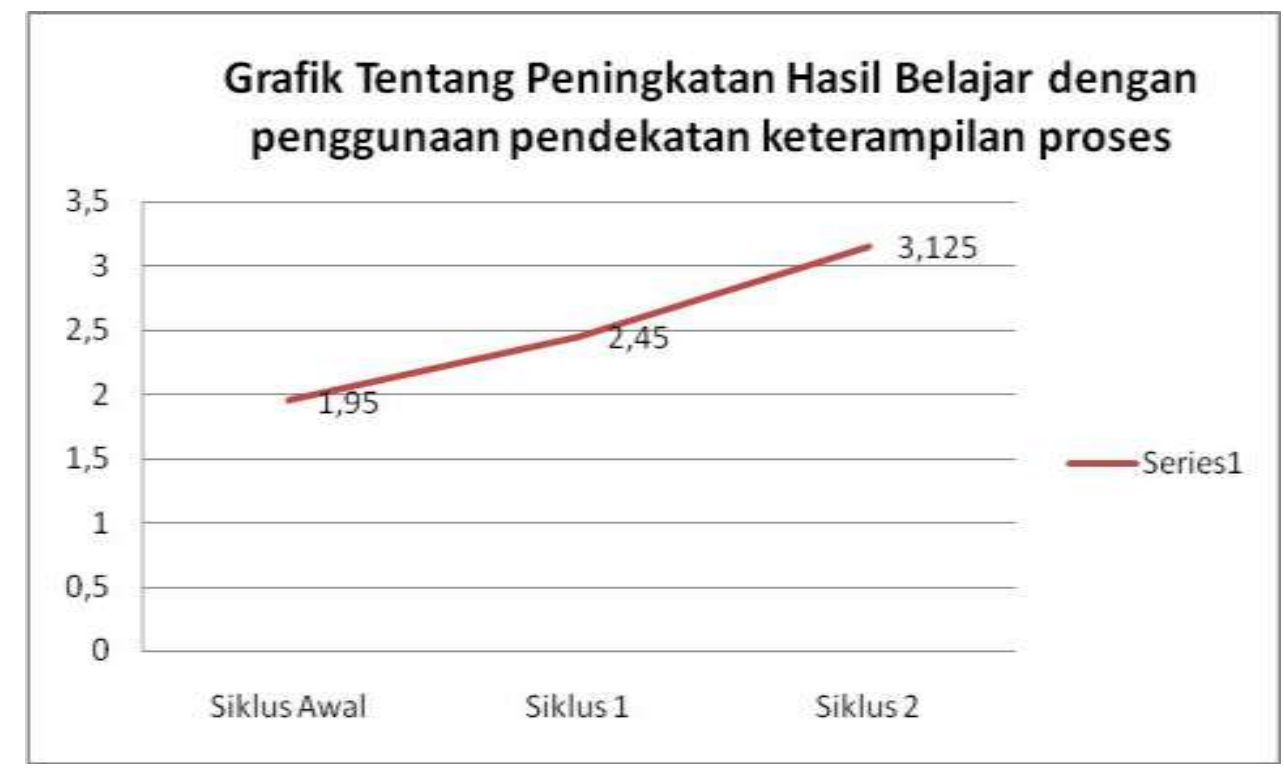

\section{SIMPULAN DAN SARAN}

\section{Simpulan}

Pendekatan Keterampilan Proses dapat meningkatkan hasil Pembelajaran Perkembangan Peserta Didik pada mahasiswa semester $2 \mathrm{C}$ Prodi Bahasa Inggris FKIP Unmas Denpasar tahun akademik 2012/2013. Hal ini dapat dilihat dari hasil yang diperoleh: (1) Tes Awal mahasiswa yang diteliti nilai rata-rata 1,95 katagori kurang, siklus I nilai rata-rata 2,45 katagori sedang dan siklus II nilai rata-rata 3,125 katagori tinggi. Sehingga dapat disimpulkan bahwa penggunaan pendekatan keterampilan proses dalam pembelajaran perkembangan peserta didik dapat meningkatkan hasil belajar dan aktvitas pembelajaran secara signifikan.

\section{Saran}

Berdasarkan hasil yang dicapai pada penelitian ini maka dapat dikemukakan beberapa saran sebagai berikut. (1) kepada dosen diharapkan selalu aktif dan kreatif dalam merancang skenario pembelajaran dengan menggunakan pendekatan keterampilan proses; (2) kepada mahasiswa dalam mempelajari suatu konsep hendaknya aktif menemukan dan mengalami langsusng permasalahan tersebut.

\section{DAFTAR PUSTAKA}

Agung AA. Gede.(1998). Pengantar Evaluasi Pengajaran. Singaraja: Sekolah Tinggi Keguruandan Ilmu Pendidikan. (1999).Metodologi Penelitian Pendidikan Singaraja: Sekolah Tinggi Keguruan dan Ilmu Pendidikan.

Arikunto. (2006) . Penelitian Tindakan Kelas. Jakarta: PT Bumi Angkasa.

H. Sunarto dkk. (2002). Perkembangan Peserta Didik. Jakarta: PT Rineka Cipta.

Mulyasa. (2005). Menjadi Guru yang Profesional. Bandung: PT Remaja Rosdakarya. 
